\title{
Synergistic Effects of Arsenite on Radiosensitization of Glioblastoma Cells
}

\author{
YASUHARU NINOMIYA ${ }^{1}$, DONG YU ${ }^{2}$, EMIKO SEKINE-SUZUKI ${ }^{3}$ and TETSUO NAKAJIMA ${ }^{1}$ \\ ${ }^{1}$ Department of Radiation Effects Research, National Institute of Radiological Sciences, \\ National Institutes for Quantum and Radiological Science and Technology, Chiba, Japan; \\ ${ }^{2}$ School of Radiological Medicine and Protection, \\ Medical College of Soochow University, Suzhou Industrial Park, Soochow, P.R. China; \\ ${ }^{3}$ Department of Basic Medical Sciences for Radiation Damages, National Institute of Radiological Sciences, \\ National Institutes for Quantum and Radiological Science and Technology, Chiba, Japan
}

\begin{abstract}
Background/Aim: Glioblastoma is a frequent type of brain tumor and is radioresistant. Arsenite, which crosses the blood-brain barrier, shows synergistic effects with radiation in vitro and in vivo. The mechanism remains unclear. Materials and Methods: As synergistic radiosensitization has been reported in p53-deficient cancer cells, radiosensitization was evaluated using the glioblastoma cell line, U87MG-E6, which harbors inactivated $p 53$, in comparison with the cell line, HCT116 p53 (-/-). Radiosensitivity was evaluated using clonogenic assays and detection of abnormal amplification of centrosomes $(A A C)$. Results: Synergistic effects of arsenite on radiosensitivity were observed in both cell lines. The radiosensitization induced by arsenite was abolished by $N$ acetyl-l-cysteine, a reactive oxygen species (ROS) scavenger. Increased radiosensitivity by arsenite was also abolished following knock-down of BRCA2. In addition, the increased radiosensitization by arsenite was correlated with $A A C$, which was abolished by BRCA2 knock-down. Conclusion: We conclude that radiosensitization by arsenite is related to ROS and BRCA2 function.
\end{abstract}

Arsenite is a well-known human carcinogen but it can also be used to treat some types of diseases including cancers $(1,2)$. Recently, arsenite has shown considerable efficacy in treating patients with acute promyelocytic leukemia (APL) $(3,4)$. In APL patients, arsenite activates numerous intracellular signal transduction pathways, resulting in induction of apoptosis,

Correspondence to: Dr. Yasuharu Ninomiya, 9-1, Anagawa-4chome, Inage-ku, Chiba, 263-8555 Japan. Tel: +81 432063079, Fax: +810432556802, e-mail: ninomiya.yasuharu@qst.go.jp

Key Words: Glioblastoma, arsenite, radiosensitization, ROS, BRCA2. promotion of differentiation, and autophagy. Not only APL tumor cells but also solid tumor cells derived from several tissues such as liver (5), prostate (6), lung (7), and brain (812) are susceptible to arsenite. In particular, a new therapeutic method for treating glioblastoma, which is a malignant brain tumor, is expected to be developed with arsenite.

Arsenite damages DNA and induces cell death in glioblastomas (8). Previously, we reported that a low concentration of arsenite that can be used clinically induces senescence in gliomas and may be an effective anticancer agent (13). Indeed, using low concentrations of arsenite (1-5 $\mu \mathrm{M})$, radiosensitizing effects of arsenite have been reported following analysis of cultured cells and xenografted tumors in mice (10). Reactive oxygen species (ROS) derived from arsenite are considered to mediate the effects of arsenite $(3,14)$. ROS damage DNA, leading to induction of DNA repair functions. Cells employ various mechanisms of DNA repair, including homologous recombination (HR). BRCA2 plays an important role in HR and is thus involved in the toxicity of arsenite (15).

In this study, we focused on the involvement of ROS and BRCA2 in synergistic radiosensitization mediated by arsenite. p53-deficient cell lines have been used in previous analyses showing that arsenite has synergistic effects on radiosensitization in xenografted tumors in mice. Therefore, our current analyses were performed using the p53-deficient glioblastoma cell line, U87MG-E6, and the HCT116 p53 $(-/-)$ cell line for comparison.

\section{Materials and Methods}

Reagents. Sodium arsenite $\left(\mathrm{NaAsO}_{2}\right)$ and $\mathrm{N}$-acetyl-1-cysteine (NAC) were obtained from Wako Pure Chemical Industries (Osaka, Osaka, Japan). Primary monoclonal anti- $\gamma$-tubulin (mouse clone GTU-88) form Sigma-Aldrich Co. (St. Louis, MO, USA) and secondary Alexa Fluor 488-conjugated goat anti-mouse IgG (Molecular Probes; Eugene, OR, USA) antibodies were used. 
Cell lines. The human malignant glioblastoma U87MG-E6 (containing viral oncoprotein E6 that inactivates p53 by accelerating its degradation) cell line was kindly provided by Dr. Mischel (16). The human colon cancer HCT116 p53 (-/-) (p53 knock-out) cell line was kindly provided by Dr. Vogelstein (17). The cells were cultured in Dulbecco's modified Eagle's medium with $4500 \mathrm{mg} / \mathrm{L}$ glucose (Sigma-Aldrich Co.; St. Louis, MO, USA) supplemented with $2 \mathrm{mM}$ L-glutamine (Gibco; Waltham, MA, USA), 5\% (v/v) heat-inactivated fetal calf serum (Biological Industries, Inc.; Beit Haemek, Israel), 100 units $/ \mathrm{mL}$ penicillin, and $100 \mu \mathrm{g} / \mathrm{mL}$ streptomycin (Invitrogen; Carlsbad, CA, USA) in a $37^{\circ} \mathrm{C}$ incubator with $5 \% \mathrm{CO}_{2}$ in air. The medium was changed every other day. Arsenite was added to medium for 4 days, and was then replaced with fresh medium without arsenite. Cells were irradiated with Xrays from an X-ray generator operated at $200 \mathrm{kV}$ and $20 \mathrm{~mA}$ with a 0.5 -mm copper and $0.5-\mathrm{mm}$ aluminum filter.

Colony-forming assay. Colony-forming assay was used to analyze survival fraction using plating efficiency. For the colony-forming assay, 300-90,000 cells were plated per dish, and 0.3125-10 $\mu \mathrm{M}$ arsenite was added to the culture $24 \mathrm{~h}$ later. NAC $(10 \mathrm{mM})$ was added to the culture before irradiation. The cells were incubated for 4 days in the presence of arsenite and/or NAC, followed by an additional 10 days of incubation in the absence of arsenite to allow colony formation. The cells were fixed and stained with a solution containing $20 \%$ methanol and $0.2 \%$ crystal violet. Colonies containing more than 50 cells were counted. At least three parallel samples were scored in three to five replicates for each treatment condition.

Immunofluorescence. Cells grown on coverslips were fixed with $4 \%$ formaldehyde in PBS for 15 min, washed with PBS, and fixed with $70 \%$ ethanol at $-20^{\circ} \mathrm{C}$ for at least $24 \mathrm{~h}$. Then, the cells were permeabilized with $0.2 \%$ Triton $\mathrm{X}-100$ for $5 \mathrm{~min}$ at $4{ }^{\circ} \mathrm{C}$ and blocked with $10 \%$ goat serum in PBS. Cells were incubated in primary antibodies for $1 \mathrm{~h}$ at $37^{\circ} \mathrm{C}$ and washed with PBS three times for 10 min each. Cells were then incubated with secondary antibodies for $1 \mathrm{~h}$ and washed with PBS three times for $10 \mathrm{~min}$ each. Coverslips were mounted in 4,6-diamidino-2-phenylindole (DAPI). Fluorescence images were captured using an Olympus DP70 fluorescence microscope. Proportion of cells with abnormal amplification of centrosomes (AAC) was determined by $\gamma$-tubulin immunofluorescence.

siRNA treatment. We used BRCA2 siRNAs with known inhibitory effects (18). BRCA2 siRNAs (Product Name: Hs_BRCA2-7_HP Validated siRNA) and negative control siRNA (Allstar negative siRNA) from Qiagen (Hilden, Germany) were used. Cells $\left(2 \times 10^{5}\right)$ were seeded in 35-mm dishes, incubated for 1 day, and transfected with $20 \mathrm{nM}$ siRNA using HiperFect transfection reagent (Qiagen; Hilden, Germany) according to the instructions of the manufacturer. Transfected cells were then cultured in normal growth medium for $48 \mathrm{~h}$ before treatment. Efficient knock-down was confirmed by quantitative RT-PCR.

Real-time reverse transcription-polymerase chain reaction (RT$P C R$ ). Total RNA was extracted from cells according to the manufacturer's instructions using the RNeasy Mini Kit (Qiagen; Hilden, Germany). mRNA silencing was quantified by real-time PCR using the ABI Prism7500 system (Applied Biosystems; Foster City, CA, USA). The mRNA value for each gene was normalized to hGAPDH (No. 431088E) mRNA levels in each RNA sample. RT-
PCR quantification of BRCA2, TaqMan Gene Expression Assays (Applied Biosystems; Foster City, CA, USA) using hBRCA2 (Hs01037420_ml) were used. All reagents necessary for running a TaqMan RT-PCR assay, including predesigned and optimized assays, were purchased from Applied Biosystems (ABI) and used according to the manufacturer's instructions. All measurements and results were analyzed with the $\mathrm{ABI}$ sequence detector software.

\section{Results}

Radiosensitizing effect of arsenite and abolishment of the radiosensitizing effect by NAC. The radiosensitizing effect of arsenite was evaluated by survival fraction (SF) analysis and determined by colony-forming assay, using the U87MG-E6 and HCT116 p53 (-/-) cell lines. Arsenite mediated radiosensitization at $0.625 \mu \mathrm{M}$ and $1.25 \mu \mathrm{M}$ in U87MG-E6 cells and at $5 \mu \mathrm{M}$ and $10 \mu \mathrm{M}$ in HCT116 p53 (-/-) cells (Figures 1A, B). To further investigate the relationship between arsenite-mediated radiosensitization and ROS, the anti-oxidant NAC was used. NAC inhibited the radiosensitizing effect of arsenite in both U87MG-E6 and HCT116 p53 (-/-) cells (Figures 1C, D).

Abolishment of the radiosensitizing effect of arsenite by BRCA2 knock-down. To investigate the involvement of BRCA2 in the radiosensitizing effect of arsenite, we knocked down BRCA2. BRCA2 knock-down in both cell lines was confirmed with quantitative RT-PCR (Figure 2A). When SF analysis was performed, X-rays alone had no effect on radiosensitivity of BRCA2 knock-down U87MG-E6 or HCT116 p53 (-/-) cells. However, treatment with arsenite alone decreased survival of BRCA2 knock-down cells from 0.099 to 0.054 for U87MG-E6 cells and from 0.097 to 0.041 for HCT 116 p53 (-/-) cells (Figure 2B, C). Interestingly, the radiosensitizing effect of the combination of arsenic and radiation was abolished by $\mathrm{BRCA} 2$ knock-down in both U87MG-E6 and HCT116 p53 (-/-) cell lines (Figure 2D, E).

Abolishment of abnormal amplification of centrosomes $(A A C)$ with the combination of radiation and arsenite in BRCA2 knock-down cells. AAC is involved in the toxicity of arsenite (19). To analyze the relationship between arseniteinduced radiosensitivity and BRCA2, we focused on AAC. AAC was analyzed 1 day after arsenite and/or radiation treatment of U87MG-E6 cells (Figure 3). Transfection of control siRNA led to an increase in AAC of $12.3 \%$ following arsenite alone treatment, $13.4 \%$ following X-ray treatment alone, and $36.2 \%$ with the combination of arsenite and radiation. Transfection of BRCA2 siRNA led to an increase in AAC-positive cells of $11.5 \%$ compared to control siRNAtransfected cells following treatment with arsenite alone. No remarkable difference was observed following X-ray treatment alone. Comparison of theoretical additive values and experimental values in the combination of arsenite and 
A

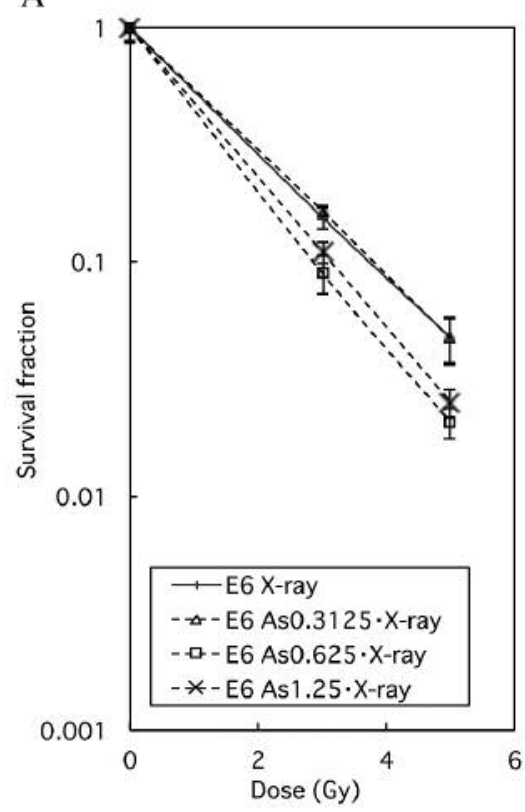

C

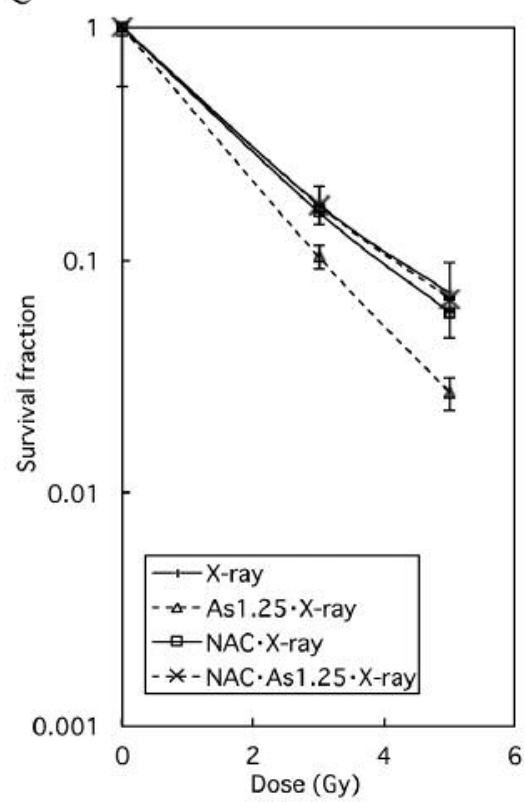

B

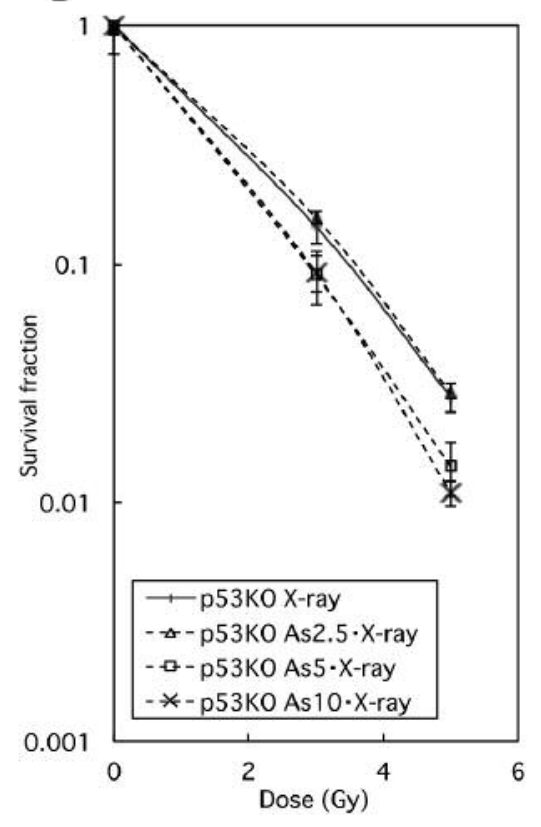

D

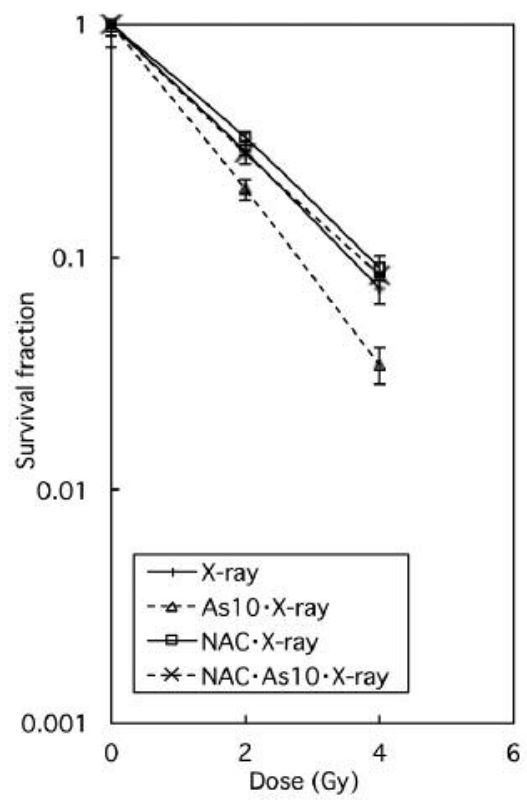

Figure 1. Radiosensitization by arsenite in p53-deficient cells and the abolishment by treatment with the anti-oxidant, NAC (10 mM). Survival fraction following irradiation and arsenite treatment of (A) U87MG-E6 cells with p53 inactivated by E6 and (B) HCT116 p53 (-/-) cells, which are p53 deficient. Cells were pre-treated with various concentrations of arsenite for $1 \mathrm{~h}$ and exposed to various doses of $X$-rays. In the case of treatment of NAC, survival fraction following irradiation and arsenite treatment of (C) U87MG-E6 and (D) HCT116 p53 (-/-) cells. Cells were pre-treated with NAC or negative control siRNA (CONi) or BRCA2 siRNA (BRCA2i) and arsenite for 1 h and exposed to various doses of X-rays. Cell survival was determined with the colony-forming assay. Data are the mean $\pm S D(n \geq 3)$.

radiation showed that experimental values were higher than the theoretical additive values and suggested synergistic effects in cells transfected with control siRNA. In cells transfected with BRCA2 siRNA, experimental values were almost the same as theoretical additive values, suggesting abolishment of synergistic effects (Figure 3B). The mechanisms underlying the radiosensitizing effects are summarized in a schematic (Figure 4). 
A

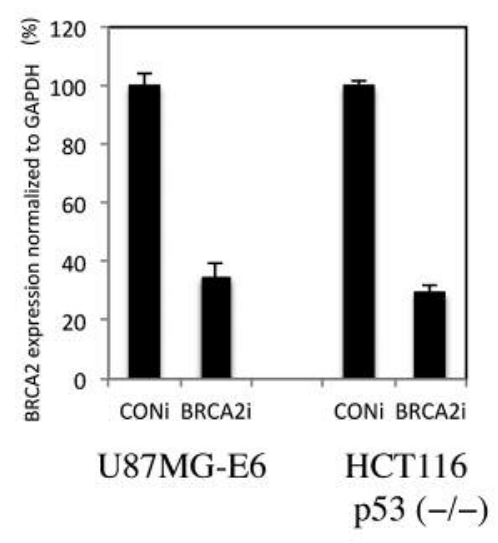

B

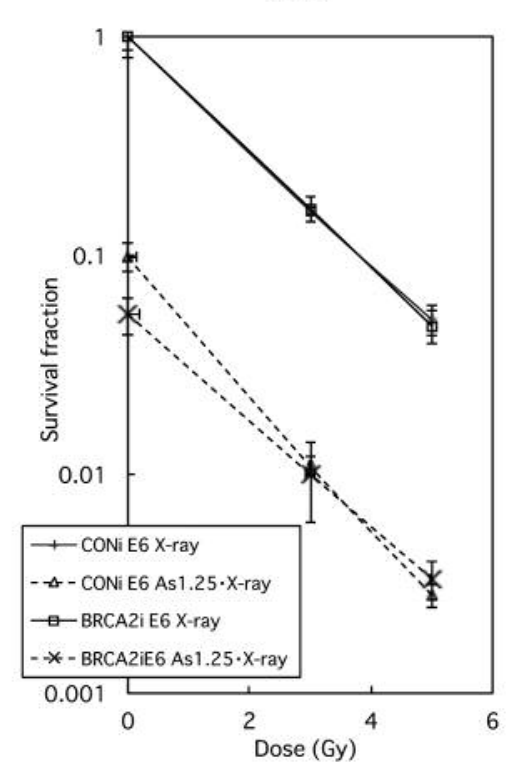

$\mathrm{D}$

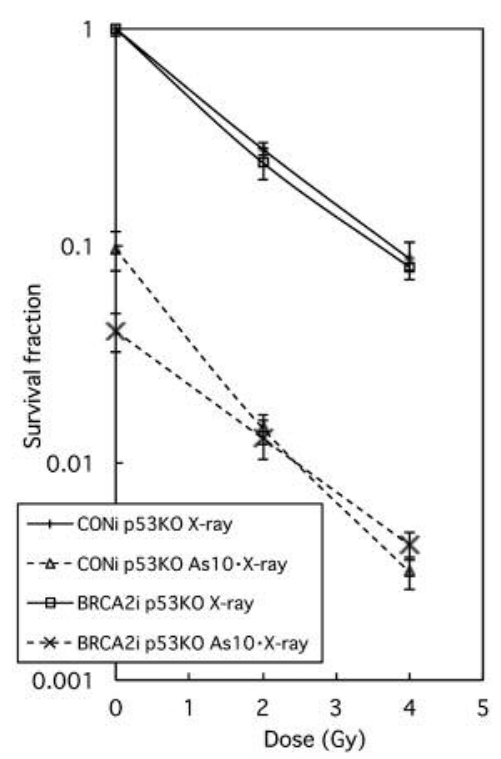

C

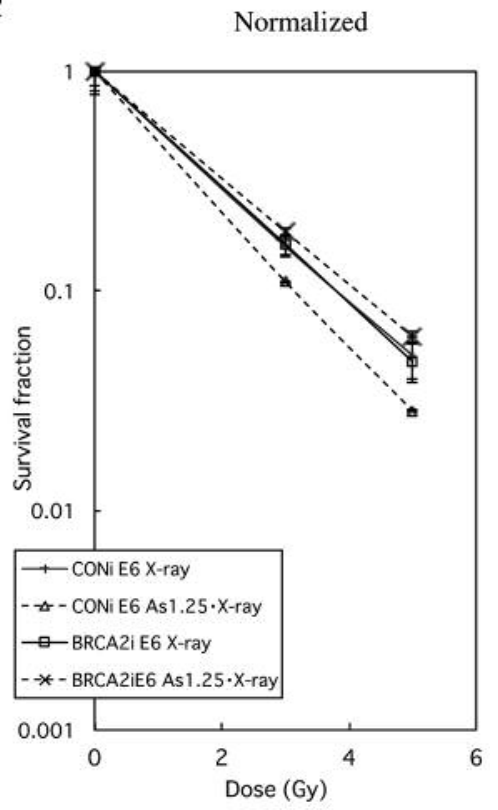

$\mathrm{E}$

Normalized

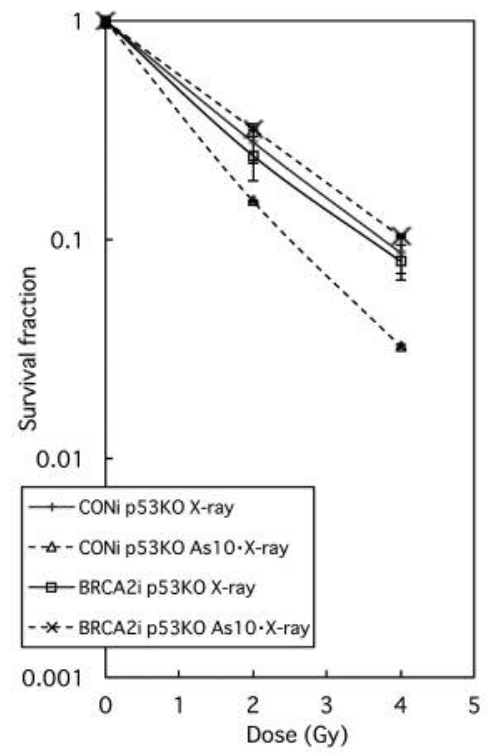

Figure 2. Radiosensitization by arsenite in p53-deficient cells was abolished by treatment with BRCA2 siRNA. (A) Efficiency of BRCA2 knockdownn with siRNA. BRCA2 and GAPDH expression was determined by quantitative RT-PCR, and relative BRCA2 expression was normalized to $G A P D H$. Data are the mean $\pm S D(n=3)$. Survival fraction following irradiation and treatment of $(B, C) U 87 M G-E 6$ and $(D, E) H C T 116 p 53(-/-)$ cells. Cells were pre-treated with BRCA2 siRNA and arsenite for $1 \mathrm{~h}$ and exposed to various doses of X-rays. Cell survival was determined with the colony-forming assay. Raw $(B, D)$ and normalized $(C, E)$ data are shown. Data are the mean $\pm S D(n \geq 3)$.

\section{Discussion}

In the present study, the U87MG-E6 glioblastoma cell line was used to analyze the radiosensitizing effect of arsenite. We demonstrated that ROS produced by arsenite contributes to the radiosensitizing effects. Furthermore, we found that arsenite may play two roles in the radiosensitizing effect: induction of DNA damage via ROS and inhibition of BRCA2 function that is required for DNA repair (Figure 4). Previous reports showed a relationship between ROS and the 
A

Control

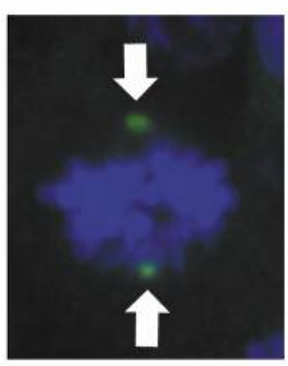

As $1.25 \mu \mathrm{M}$

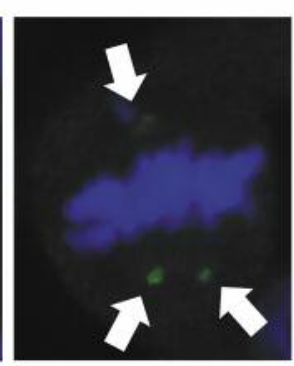

B

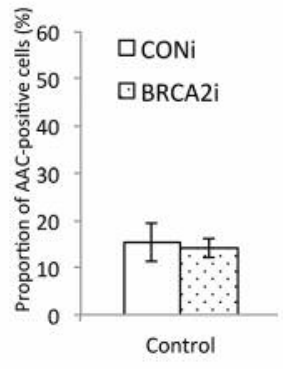

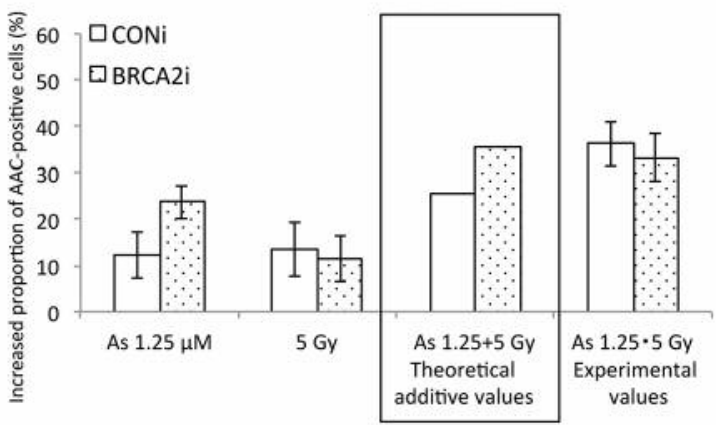

Figure 3. Synergistic increase in abnormal amplification of centrosomes in mitotic. U87MG-E6 cells irradiated and treated with arsenite was abolished by treatment with BRCA2 siRNA. (A) Micrographs of $\gamma$-tubulin immunofluorescence obtained from U87MG-E6 cells treated with arsenite. Typical photographs are shown at 600x. (B) Proportion of cells with abnormal amplification of centrosomes of total of 40 mitotic U87MG-E6 cells 1 day after irradiation in the presence or absence of arsenite. Data are the mean $\pm S D(n \geq 3)$.

radiosensitizing effect of arsenite. ROS has been directly measured $(10,20)$. In this study, we investigated the relationship between ROS and the radiosensitizing effect of arsenite using SF analysis. NAC, a widely used anti-oxidant, inhibited the radiosensitizing effect, strongly suggesting that ROS contributed to the radiosensitizing effect of arsenite. Arsenite-induced ROS causes DNA damage $(21,22)$. ROS produced by arsenite causes SSBs, which are converted to double-strand breaks (DSBs) during replication $(23,24,25)$. Thus, DNA damage generated by ROS may contribute to the radiosensitizing effect of arsenite by producing DSBs.

Non-homologous end joining and HR are important mechanisms of DNA repair (26). BRCA2, which participates in HR, is involved in the toxicity of arsenite (15). To investigate the relationship between BRCA2 and the radiosensitizing effect of arsenite, we examined the radiosensitivity in BRCA2 knock-down cells. The radiosensitizing effect of arsenite with $\mathrm{SF}$ analysis was abolished in BRCA2 knock-down cells. As shown in Figures 2B and D, BRCA2 knock-down increased the sensitivity to treatment with arsenic alone, and the sensitivity was increased to almost the same value as that with the combination of arsenite and radiation. This implies that BRCA2 was involved in the radiosensitizing effect of arsenite and that inhibition of BRCA2 function may be directly linked to the radiosensitizing mechanism. Arsenite may suppress DNA repair that is normally mediated by BRCA2. Thus, BRCA2 knock-down may increase sensitivity to arsenite and abolish the radiosensitizing effect (Figure 4). The mechanism through which BRCA2 is involved in the radiosensitizing effect of arsenite is still unclear. The type of DNA damage caused by the combination of arsenite and radiation may be important. Complex DNA damage is more

\section{Arsenite and/or radiation}

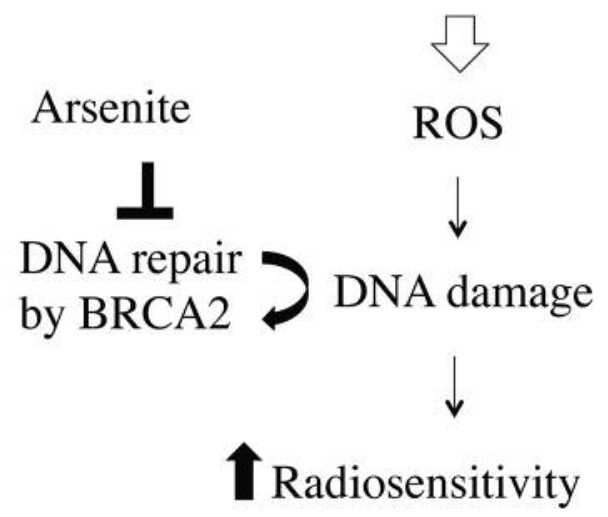

Figure 4. Schematic representation of radiosensitization by arsenite.

difficult to repair than simple DNA damage $(27,28)$. Because SSBs are generated by arsenite, and DSBs are generated by radiation, the radiosensitizing effect may be evoked by complex DNA damage consisting of SSBs and DSBs caused by the combination of arsenite and radiation. Because BRCA2 mainly repairs complex DNA damage (29), the observed radiosensitizing effect may be abolished by BRCA2 knock-down.

We also found a change in AAC that was correlated with the radiosensitizing effect of arsenite in SF analysis. AAC is involved in the toxicity of arsenite (19) and radiation (30), and is an indicator (31) of mitotic catastrophe. Mitotic catastrophe causes cytotoxicity because DNA cannot be properly segregated into two daughter cells in the $\mathrm{M}$ phase 
of cell division. Also, the radiosensitizing effect of arsenite on AAC was abolished with BRCA2 knock-down. We believe that the radiosensitizing effect was due to the function of ROS and BRCA2, and as a result, AAC was detected as the endpoint. The results of the analysis of AAC in BRCA2 knock-down cells showed a similar trend as the $\mathrm{SF}$ analysis (Figure 4). AAC is detected following replication that occurs in the presence of DNA damage (32). The AAC results strongly suggested that DNA damage was involved in the radiosensitizing effect of arsenite.

Arsenite is a promising radiosensitizing agent. Though effects of some metal-related elements on radio-sensitivity have been reported (33-35), gadolinium (Gd), a metal-related element, has also been reported to have radiosensitizing effects similar to arsenite. Gd mediates the radiosensitizing effect via ROS that is generated from the metal surface, and the characteristics of the radiosensitivity may be similar to those of arsenite $(36,37)$. A phase I clinical trial of combination therapy of arsenite and radiation for patients with solid tumors has been completed, and the safety of arsenite as a clinical drug was proven $(38,39)$. Our study showed that arsenite has synergistic effects on radiosensitivity via ROS and BRCA2 function. Analyses of the synergistic effects of arsenite in radiosensitivity will contribute to improvements in radiotherapy using arsenite or other metal-related elements such as Gd.

\section{Acknowledgements}

The Authors would like to thank Dr. Paul S. Mischel for supplying the U87M-E6 cell line, Dr. Bert Vogelstein for supplying the HCT116 p53 (-/-) cell line, and Drs. Tatsuhiko Imaoka, Kazuhiro Daino, Shizuko Kakinuma, Sentaro Takahashi, and Ohtsura Niwa for their valuable help in preparation of the manuscript. This article was funded by our institution's budget (National Institute of Radiological Sciences), Chiba, Japan.

\section{References}

1 Murgo AJ: Clinical trials of arsenic trioxide in hematologic and solid tumors: Overview of the national cancer institute cooperative research and development studies. Oncologist 6(Suppl 2): 22-28, 2001.

2 Cui X, Kobayashi Y, Akashi M and Okayasu R: Metabolism and the paradoxical effects of arsenic: Carcinogenesis and anticancer. Curr Med Chem 15(22): 2293-2304, 2008.

3 Liu SX, Athar M, Lippai I, Waldren C and Hei TK: Induction of oxyradicals by arsenic: Implication for mechanism of genotoxicity. Proc Natl Acad Sci USA 98(4): 1643-1648, 2001.

4 Zheng PZ, Wang KK, Zhang QY, Huang QH, Du YZ, Zhang QH, Xiao DK, Shen SH, Imbeaud S, Eveno E, Zhao CJ, Chen YL, Fan HY, Waxman S, Auffray C, Jin G, Chen SJ, Chen Z and Zhang J: Systems analysis of transcriptome and proteome in retinoic acid/arsenic trioxide-induced cell differentiation/ apoptosis of promyelocytic leukemia. Proc Natl Acad Sci USA 102(21): 7653-7658, 2005.
5 Cui X, Wakai T, Shirai Y, Yokoyama N, Hatakeyama K and Hirano S: Arsenic trioxide inhibits dna methyltransferase and restores methylation-silenced genes in human liver cancer cells. Hum Pathol 37(3): 298-311, 2006.

6 Maeda H, Hori S, Nishitoh H, Ichijo H, Ogawa O, Kakehi Y and Kakizuka A: Tumor growth inhibition by arsenic trioxide (As2O3) in the orthotopic metastasis model of androgen-independent prostate cancer. Cancer Res 61(14): 5432-5440, 2001.

7 Pettersson HM, Pietras A, Munksgaard Persson M, Karlsson J, Johansson L, Shoshan MC and Påhlman S: Arsenic trioxide is highly cytotoxic to small cell lung carcinoma cells. Mol Cancer Ther 8(1): 160-170, 2009

8 Kanzawa T, Kondo Y, Ito H, Kondo S and Germano I: Induction of autophagic cell death in malignant glioma cells by arsenic trioxide. Cancer Res 63(9): 2103-2108, 2003.

9 Haga N, Fujita $\mathrm{N}$ and Tsuruo T: Involvement of mitochondrial aggregation in arsenic trioxide (As2O3)-induced apoptosis in human glioblastoma cells. Cancer Sci 96(11): 825-833, 2005.

10 Ning S and Knox SJ: Increased cure rate of glioblastoma using concurrent therapy with radiotherapy and arsenic trioxide. Int J Radiat Oncol Biol Phys 60(1): 197-203, 2004.

11 Qian W, Liu J, Jin J, Ni W and Xu W: Arsenic trioxide induces not only apoptosis but also autophagic cell death in leukemia cell lines via up-regulation of beclin-1. Leuk Res 31(3): 329339, 2007.

12 Kanzawa T, Zhang L, Xiao L, Germano IM, Kondo Y and Kondo S: Arsenic trioxide induces autophagic cell death in malignant glioma cells by upregulation of mitochondrial cell death protein bnip3. Oncogene 24(6): 980-991, 2005.

13 Ninomiya Y, Cui X, Yasuda T, Wang B, Yu D, Sekine-Suzuki E and Nenoi M: Arsenite induces premature senescence via p53/p21 pathway as a result of dna damage in human malignant glioblastoma cells. BMB Rep 47(10): 575-580, 2014.

14 Hei TK and Filipic M: Role of oxidative damage in the genotoxicity of arsenic. Free Radic Biol Med 37(5): 574-581, 2004.

15 Ying S, Myers K, Bottomley S, Helleday T and Bryant HE: Brca2-dependent homologous recombination is required for repair of arsenite-induced replication lesions in mammalian cells. Nucleic Acids Res 37(15): 5105-5113, 2009.

16 Wang Y, Zhu S, Cloughesy TF, Liau LM and Mischel PS: P53 disruption profoundly alters the response of human glioblastoma cells to dna topoisomerase i inhibition. Oncogene 23(6): 12831290, 2004.

17 Bunz F, Dutriaux A, Lengauer C, Waldman T, Zhou S, Brown JP, Sedivy JM, Kinzler KW and Vogelstein B: Requirement for p53 and p21 to sustain g2 arrest after dna damage. Science 282(5393): 1497-1501, 1998.

18 Yu D, Sekine E, Fujimori A, Ochiya T and Okayasu R: Down regulation of brca2 causes radio-sensitization of human tumor cells in vitro and in vivo. Cancer Sci 99(4): 810-815, 2008.

19 Yih LH, Tseng YY, Wu YC and Lee TC: Induction of centrosome amplification during arsenite-induced mitotic arrest in cgl-2 cells. Cancer Res 66(4): 2098-2106, 2006.

20 Chiu HW, Chen YA, Ho SY and Wang YJ: Arsenic trioxide enhances the radiation sensitivity of androgen-dependent and -independent human prostate cancer cells. PLoS One 7(2): e31579, 2012.

21 Meriyani Odyuo M and Sharan RN: Differential dna strand breaking abilities of $*$ oh and ros generating radiomimetic chemicals and gamma-rays: Study of plasmid dna, pmta4, in vitro. Free Radic Res 39(5): 499-505, 2005. 
22 Bach J, Peremartí J, Annangi B, Marcos R and Hernández A: Oxidative dna damage enhances the carcinogenic potential of in vitro chronic arsenic exposures. Arch Toxicol 90(8): 1893-1905, 2016.

23 Saleh-Gohari N, Bryant HE, Schultz N, Parker KM, Cassel TN and Helleday T: Spontaneous homologous recombination is induced by collapsed replication forks that are caused by endogenous dna single-strand breaks. Mol Cell Biol 25(16): 7158-7169, 2005.

24 Kligerman $\mathrm{AD}$ and Tennant $\mathrm{AH}$ : Insights into the carcinogenic mode of action of arsenic. Toxicol Appl Pharmacol 222(3): 281288, 2007

25 Kligerman AD, Malik SI and Campbell JA: Cytogenetic insights into dna damage and repair of lesions induced by a monomethylated trivalent arsenical. Mutat Res 695(1-2): 2-8, 2010.

26 Cho NW and Greenberg RA: Dna repair: Familiar ends with alternative endings. Nature 518(7538): 174-176, 2015.

27 Xue L, Furusawa Y, Okayasu R, Miura M, Cui X, Liu C, Hirayama R, Matsumoto Y, Yajima H and Yu D: The complexity of dna double strand break is a crucial factor for activating atr signaling pathway for $\mathrm{g} 2 / \mathrm{m}$ checkpoint regulation regardless of atm function. DNA Repair (Amst) 25: 72-83, 2015.

28 Averbeck NB, Ringel O, Herrlitz M, Jakob B, Durante M and Taucher-Scholz G: Dna end resection is needed for the repair of complex lesions in g1-phase human cells. Cell Cycle 13(16): 2509-2516, 2014.

$29 \mathrm{Li} \mathrm{X}$ and Heyer WD: Homologous recombination in dna repair and dna damage tolerance. Cell Res 18(1): 99-113, 2008.

30 Eriksson D, Löfroth PO, Johansson L, Riklund KA and Stigbrand T: Cell cycle disturbances and mitotic catastrophes in hela hep2 cells following 2.5 to 10 gy of ionizing radiation. Clin Cancer Res 13(18 Pt 2): 5501s-5508s, 2007.

31 Löffler H, Lukas J, Bartek J and Krämer A: Structure meets function - centrosomes, genome maintenance and the dna damage response. Exp Cell Res 312(14): 2633-2640, 2006.

32 Hut HM, Lemstra W, Blaauw EH, Van Cappellen GW, Kampinga $\mathrm{HH}$ and Sibon OC: Centrosomes split in the presence of impaired dna integrity during mitosis. Mol Biol Cell 14(5): 1993-2004, 2003.
33 Magda D and Miller RA: Motexafin gadolinium: A novel redox active drug for cancer therapy. Semin Cancer Biol 16(6): 466476, 2006.

34 Pottier A, Borghi E and Levy L: New use of metals as nanosized radioenhancers. Anticancer Res 34(1B): 443-453, 2014.

35 Falzone N, Bohm L, Swarts JC and Van Rensburg CEJ: Radiosensitization of cho cells by two novel rhodium complexes under oxic and hypoxic conditions. Anticancer Res 26(1A): 147$152,2006$.

36 Seo SJ, Han SM, Cho JH, Hyodo K, Zaboronok A, You H, Peach K, Hill MA and Kim JK: Enhanced production of reactive oxygen species by gadolinium oxide nanoparticles under coreinner-shell excitation by proton or monochromatic $\mathrm{x}$-ray irradiation: Implication of the contribution from the interatomic de-excitation-mediated nanoradiator effect to dose enhancement. Radiat Environ Biophys 54(4): 423-431, 2015.

37 Miladi I, Aloy MT, Armandy E, Mowat P, Kryza D, Magné N, Tillement O, Lux F, Billotey C, Janier M and Rodriguez-Lafrasse C: Combining ultrasmall gadolinium-based nanoparticles with photon irradiation overcomes radioresistance of head and neck squamous cell carcinoma. Nanomedicine 11(1): 247-257, 2015.

38 Lai YL, Chang HH, Huang MJ, Chang KH, Su WH, Chen HW, Chung $\mathrm{CH}$, Wang WY, Lin LH and Chen YJ: Combined effect of topical arsenic trioxide and radiation therapy on skininfiltrating lesions of breast cancer-a pilot study. Anticancer Drugs 14(10): 825-828, 2003.

39 Grimm SA, Marymont M, Chandler JP, Muro K, Newman SB, Levy RM, Jovanovic B, McCarthy K and Raizer JJ: Phase I study of arsenic trioxide and temozolomide in combination with radiation therapy in patients with malignant gliomas. J Neurooncol 110(2): 237-243, 2012.
Received June 14, 2017

Revised July 3, 2017

Accepted July 4, 2017 